\title{
The plasticity of HTLV-1 infected CD4+CD25 +CCR4+ T-cells through HTLV-1 tax in HAM/TSP
}

\author{
Natsumi Araya' ${ }^{1}$ Tomoo Sato ${ }^{1}$, Atae Utsunomiya ${ }^{2}$, Hitoshi Ando ${ }^{1}$, Naoko Yagishita', Mari Kannagi ${ }^{3}$, \\ Tatsufumi Nakamura ${ }^{4}$, Yuetsu Tanaka ${ }^{5}$, Steven Jacobson ${ }^{6}$, Yoshihisa Yamano ${ }^{{ }^{*}}$ \\ From 15th International Conference on Human Retroviruses: HTLV and Related Viruses \\ Leuven and Gembloux, Belgium. 5-8 June 2011
}

Recently, it has become increasingly clear that some committed effecter and regulatory $\mathrm{T}$ (Treg) cells are not stable, and the plasticity of committed T-cells may be related to autoimmunity and inflammatory disease. However, the environmental (extrinsic) molecules that allow for plasticity have not yet been clearly understood.

In Human T-lymphotropic virus type 1 (HTLV-1) associated myelopathy /tropical spastic paraparesis (HAM/TSP), the pathogenesis is known as HTLV-1 infected CD4+ T-cells triggered hyper immune response, which leads to chronic inflammation of the central nervous system. In our previous study, we demonstrated that the majority of CD4+CD25+CCR4+ T-cells were infected with HTLV-1 and that this T-cell subset was increased in HAM/TSP. Although CD4 $+\mathrm{CD} 25+\mathrm{CCR} 4+\mathrm{T}$-cells of healthy condition include suppressive $\mathrm{T}$ cell subsets such as Treg and Th2, this $\mathrm{T}$-cell subset becomes Th1-like cells with overproduction of IFN- $\gamma$ in HAM/TSP patients (PLoS ONE 2009). Since HTLV-1 tax is known to up-regulate the expression of several proinflammatory cytokines, and importantly, the level of HTLV-1 tax mRNA expression is reported to correlate with disease severity in HAM/TSP patients, we hypothesize that HTLV-1 tax may convert HTLV-1 infected T-cells into abnormal IFN- $\gamma$ producing Th1-like T-cells in HAM/TSP. In this study, we present the molecular mechanisms underlying the plasticity of HTLV-1 infected CD4+CD25+CCR4+ T-cells through HTLV-1 tax.

\section{Author details}

'Department of Molecular Medical Science, Institute of Medical Science, St. Marianna University School of medicine, Kawasaki, Japan. ${ }^{2}$ Department of Hematology, Imamura Bun-in Hospital, Kagoshima, Japan. ${ }^{3}$ Department of Immunotherapeutics, Tokyo Medical and Dental University, Graduate School, Tokyo, Japan. ${ }^{4}$ Department of Molecular Microbiology and Immunology, Graduate School of Biomedical Sciences, Nagasaki University, Nagasaki, Japan. ${ }^{5}$ Department of Immunology, Graduate School of Medicine, University of the Ryukyus, Okinawa, Japan. ${ }^{6}$ Viral Immunology Section,

Neuroimmunology Branch, National Institute of Neurological Disorders and Stroke, National Institutes of Health, Bethesda, Maryland, USA.

Published: 6 June 2011

doi:10.1186/1742-4690-8-S1-A104

Cite this article as: Araya et al.: The plasticity of HTLV-1 infected CD4 +CD25+CCR4+ T-cells through HTLV-1 tax in HAM/TSP. Retrovirology 2011 8(Suppl 1):A104.

\footnotetext{
* Correspondence: yyamano@marianna-u.ac.jp

'Department of Molecular Medical Science, Institute of Medical Science, St. Marianna University School of medicine, Kawasaki, Japan

Full list of author information is available at the end of the article
}

Submit your next manuscript to BioMed Central and take full advantage of:

- Convenient online submission

- Thorough peer review

- No space constraints or color figure charges

- Immediate publication on acceptance

- Inclusion in PubMed, CAS, Scopus and Google Scholar

- Research which is freely available for redistribution 